\title{
OS TRÊS MOMENTOS PEDAGÓGICOS COMO METODOLOGIA PARA O ENSINO HÍBRIDO NO ATENDIMENTO EDUCACIONAL ESPECIALIZADO
}

\author{
Andressa Venturini \\ Universidade Franciscana - UFN \\ dessaventurini8@gmail.com \\ Valdir Pretto \\ Universidade Franciscana - UFN \\ prettov@gmail.com \\ Ana Marli Bulegon \\ Universidade Franciscana - UFN \\ anabulegon@gmail.com
}

\section{Resumo}

O presente trabalho é um relato sobre o Ensino Híbrido, desenvolvido com a metodologia dos Três Momentos Pedagógicos (TMP), entre estudantes de uma escola do campo no interior do Rio Grande do Sul, no atendimento educacional especializado. Neste ano de pandemia, em que o ensino precisou ser remoto, buscou-se uma forma diferenciada de abordar conhecimentos e experiências do cotidiano do aluno, como um modo de dialogar e refletir sobre as vidas e o trabalho no campo. Utilizamos os ambientes virtuais de aprendizagem (AVA): whatsapp, facebook e youtube, além de vídeo aulas e do power point, enquanto ferramenta de autoria. As atividades foram síncronas e assíncronas com o uso do aparelho de celular, as quais apresentaram resultados positivos, considerando que todas foram entregues com êxito pelos seus participantes, sendo essas, desenvolvidas por meio das tecnologias.

Palavras chave: Educação Inclusiva; Aprendizagem; Qualidade de vida

\section{Introdução}

O presente trabalho é um relato sobre o desenvolvimento de atividades de ensino na modalidade de Ensino Híbrido (EH), com alunos em atendimento educacional especializado (AEE) de uma escola do campo, no interior do Rio Grande do Sul. A realização desse trabalho originou-se dos estudos realizados sobre ensino Híbrido na disciplina Educação Mediada por Tecnologias Digitais, no curso de Mestrado, da PósGraduação no Ensino de Ciência e Matemática (PPGECIMAT), da Universidade Franciscana (UFN).

A aplicação do estudo está pautada por períodos de aula síncrona e assíncrona: trabalho em equipe em tempo real e trabalho individual em casa, consolidando o ensino híbrido. Buscamos propiciar diferentes atividades de forma síncrona e assíncrona, com o uso de aparelhos de celular, pois é o meio de acesso à internet dos alunos em suas casas. Os conceitos foram discutidos, entre professor e aluno, com apoio de orientação 
presencial e remota, com o objetivo mediar o desenvolvimento das atividades por parte dos alunos (fotos, vídeos, releitura, produção e apresentação do power point).

O trabalho foi realizado com três alunos com dificuldades específicas de aprendizagem (DEA) da turma do $6^{\circ}$ ano do Ensino Fundamental. A escolha desta escola ocorreu que uma das autoras atua como Psicopedagoga, e buscou-se uma interação com os alunos DEA neste momento de isolamento social, através de uma abordagem que os estudantes dominassem, sendo o tema analisado a qualidade de vida dos alunos do campo.

\section{Atendimento Educacional Especializado e o Ensino Remoto}

$\mathrm{O}$ atendimento educacional especializado, neste momento de isolamento social, suas atividades, são possíveis através do ensino remoto, quando professor e aluno desenvolvem trabalhos através das tecnologias digitais, onde não há a necessidade de estar na escola, pois a comunicação ocorre em diferentes espaços utilizando o celular.

Segundo Tomazinho (2020, p. 01) "ensino remoto porquê de fato professores e alunos estão impedidos por decreto do Ministério da Educação e Secretariais Estaduais de Educação de frequentarem escolas, evitando a disseminação do vírus, seguindo os planos de contingências orientados pelo Ministério da Saúde".

O modo de ensino utilizado acontece com o uso do ambiente virtual da aprendizagem (whatsapp) com vídeos chamadas e, também com o grupo da escola (Whatsapp), assim como o uso de ferramenta de autoria (powerpoint).

\section{Modalidade de Ensino Híbrido}

Visto a situação planetária, causada pela pandemia, o modelo de Ensino Híbrido tem sido muito abordado nas lives de especialistas em Educação, com ou sem o uso de Tecnologias de Informação e Comunicação (TIC).

De acordo com Schiehl e Gasparini (2017), o ensino híbrido (EH) é um modelo de educação formal que se caracteriza por mesclar dois modos de ensino: o de forma tradicional e o on-line, valorizando também a interação e o aprendizado coletivo e colaborativo. Os modelos de EH, elencados por Schiehl e Gasparini (2017), encontrados em suas pesquisas são: 
Quadro 1 - Modelos de Ensino Híbrido

\begin{tabular}{|l|l|}
\hline Modelos de Ensino Híbrido & \multicolumn{1}{|c|}{ Descrição } \\
\hline $\begin{array}{l}\text { Suplementar (face to face } \\
\text { (F2F) + on-line) }\end{array}$ & $\begin{array}{l}\text { O estudante trabalha em sala de aula, com atendimento do } \\
\text { professor, e posteriormente continua com seus estudos em } \\
\text { ambientes virtuais. }\end{array}$ \\
\hline $\begin{array}{l}\text { Sala de aula Invertida } \\
\text { (Flipped Classroom) }\end{array}$ & $\begin{array}{l}\text { O estudante estuda inicialmente em ambientes virtuais e } \\
\text { depois produz projetos e atividade em sala de aula; }\end{array}$ \\
\hline Laboratório Rotacional & $\begin{array}{l}\text { Desenvolve atividades em uma sala de aula tradicional e } \\
\text { as atividades on-line são produzidas na sala } \\
\text { informatizada; }\end{array}$ \\
\hline Rotação de Estudos & $\begin{array}{l}\text { O estudante desenvolve uma rotina de estudos em sala de } \\
\text { aula com acompanhamento do professor presencial e em } \\
\text { ambientes virtuais com auxílio de um professor on-line. }\end{array}$ \\
\hline Síncronono & $\begin{array}{l}\text { Caracteriza uma comunicação de sala de aula, com apoio } \\
\text { do professor aos estudantes presenciais e remotos. } \\
\text { Através do uso de ferramentas integradas a uma } \\
\text { plataforma de aprendizagem, os estudantes híbridos } \\
\text { podem estabelecer uma comunicação síncrona ou } \\
\text { assíncrona, usando e-mail, fóruns de discussão e blogs. } \\
\text { Podem trabalhar de forma colaborativa em projetos por } \\
\text { disciplina. O estudante tem autonomia na escolha do } \\
\text { ambiente de aprendizagem que mais lhe agrada, que são: } \\
\text { o F2F, aprendizagem online síncrona, aprendizagem on- } \\
\text { line assíncrona e aprendizagem aberta. Podem utilizar } \\
\text { combinações personalizadas de aplicativos Web 2.0 } \\
\text { como: Etherpad, Piazza, Google Hangouts e Google } \\
\text { Formulários, para momentos de interação. }\end{array}$ \\
\hline Grupo Dual-Colaborativo & $\begin{array}{l}\text { Utilizando o Portfólio eletrônico de Grupos (PEG) um } \\
\text { grupo de estudantes e um facilitador trabalham com a } \\
\text { construção de saberes em cenários protegidos e } \\
\text { controlados. O projeto usa vídeos, situações simuladas, } \\
\text { práticas ou situações problemas para discutir assuntos e } \\
\text { posteriormente postam no ambiente PEG para que outros } \\
\text { estudantes interajam e colabore nas discussões. }\end{array}$ \\
\hline
\end{tabular}

Fonte: Schiehl e Gasparini (2017)

Destaca-se o modelo de Ensino Híbrido, do tipo Colaborativo Síncrono, é o mais indicado para o atendimento de alunos do AEE, por permitir a interação entre professores e alunos.

Plano de ensino híbrido com alunos com Dificuldades Específicas de Aprendizagem do $6^{\circ}$ ano- Anos Finais (AF)

Para Clayton Christensen Institute, EUA (2020), o Ensino Híbrido é um programa de Educação Formal no qual um aluno aprende, pelo menos em parte, por 
meio do ensino online, o controle do estudante sobre o tempo, lugar, modo e ritmo do estudo, e uma parte em uma localidade física supervisionada, fora da residência.

O plano de ensino com alunos com DEA do $6^{\circ}$ ano- AF, pertencentes ao público da EI, teve uma perspectiva de tornar o aluno autônomo na construção da aprendizagem.

Objetivo produzir um plano de ensino híbrido utilizando a metodologia dos três momentos pedagógicos para alunos da educação inclusiva com dificuldades especificas da aprendizagem assim mantendo o vínculo com a escola e fortalecendo a aprendizagem.

A turma do $\mathrm{AEE}$ do $6^{\circ}$ ano onde foi realizada a tarefa é composta por três alunos com DEA, totalizando 2 meninos e 1 menina, com idade 13 a 15 anos. Estes educandos, são filhos de agricultores produtores de fumo ou trabalham na lavoura, há discurso da necessidade de ir embora para cidade por falta de incentivo do governo e pela falta de qualidade da internet refletindo na economia e sustento do jovem do campo.

Possibilitou-se a liberdade de criação e produção do seu desenvolvimento com tema qualidade de vida dos alunos do campo através da metodologia dos três momentos pedagógicos. Teve como tema a "Qualidade de vida dos alunos do campo".

Quadro 2: as atividades e a sequência da metodologia três momentos pedagógicos

\begin{tabular}{|l|l|l|l|}
\hline Atividades & $\begin{array}{l}\text { Metodologia } \\
\text { TMP }\end{array}$ & Recursos & Ações \\
\hline $\begin{array}{l}\text { Atividade 1 } \\
\text { - Investigar } \\
\text { quais } \\
\text { atividades } \\
\text { os alunos } \\
\text { do campo } \\
\text { desenvolve } \\
\text { m em casa? }\end{array}$ & & $\begin{array}{l}\text { Aparelho } \\
\text { Celular }\end{array}$ & Tirar fotos de suas atividades cotidianas \\
\hline $\begin{array}{l}\text { Atividade 2 } \\
\text { - Orientação } \\
\text { os alunos a } \\
\text { escrever } \\
\text { frases em } \\
\text { relação a } \\
\text { foto. }\end{array}$ & & & \\
\hline $\begin{array}{l}\text { Atividade 3 } \\
-\quad \text { Solicitar } \\
\text { aos alunos } \\
\text { que façam }\end{array}$ & & & $\begin{array}{l}\text { Ocrever pequenas frases relatando o que } \\
\text { Oparece nas fotos }\end{array}$ \\
\hline
\end{tabular}




\begin{tabular}{|c|c|c|}
\hline $\begin{array}{l}\text { uma } \\
\text { releitura da } \\
\text { foto. }\end{array}$ & & \\
\hline $\begin{array}{l}\text { Atividade } 4 \\
\text { - Assistir } \\
\text { três vídeos } \\
\text { com o tema } \\
\text { "a vida no } \\
\text { campo" }\end{array}$ & $\mathrm{OC}$ & $\begin{array}{l}\text { Assistir os } \\
\text { https://www.youtube.com/results?search_q } \\
\text { uery=zona+urbana+x+zona+rural\%2C } \\
\text { https://www.youtube.com/results?search_q } \\
\text { uery=Chico+Bento\%3A+a+hora+da+on\% } \\
\text { C3\%A7a+beber+\%C3\%A1gua+ } \\
\text { https://www.youtube.com/results?search_q } \\
\text { uery=Chico+Bento+na+ro\%C3\%A7a+\%C } \\
\text { 3\%A9+diferente. }\end{array}$ \\
\hline $\begin{array}{l}\text { Atividade } 5 \\
\text {-Organizar } \\
\text { e apresentar } \\
\text { o power } \\
\text { point } \\
\text { unindo o } \\
\text { material } \\
\text { coletivamen } \\
\text { te. }\end{array}$ & $\mathrm{AC}$ & Produzir apresentações no PowerPoint. \\
\hline
\end{tabular}

Fonte: Elaborado pelos autores

Por essa razão foram usadas referências que dialogam com a ideia de Paulo Freire e apresentam uma proposição para atuação do psicopedagogo, sob os princípios da dialogicidade e problematização, os três momentos, são eles Delizoicov; Angotti; Pernambuco (2011), os quais ressaltam a articulação entre a Educação do Campo.

[...] a abordagem de conhecimentos científicos é o ponto de chegada, quer da estruturação do conhecimento pragmático quer da aprendizagem dos alunos, ficando o ponto de partida com os temas e as situações significativas que originam, de um lado, a seleção e organização de conteúdos, ao serem articulados com a estrutura do conhecimento cientifico, e de outro, o início do processo de dialógico e problematizador. (DELIZOICOV, ANGOTTI, PERNAMBUCO, 2011, p.194).

Esse trabalho foi organizado de acordo com a metodologia dos Três Momentos Pedagógicos de (DELIZOICOV e ANGOTTI, 1992) que compreende as etapas: Problematização Inicial (PI), Organização do Conhecimento (OC) e Aplicação do Conhecimento (AC).

Problematização Inicial (PI): deve partir do princípio que a "problematização é fazer com que o aluno sinta a necessidade da aquisição de outros conhecimentos que ainda não detém, ou seja, procura-se configurar a situação em discussão como um problema que precisa ser enfrentado" (DELIZOICOV, 2005, p.12). 
A PI aconteceu inicialmente com a discussão sobre a qualidade de vida do aluno do campo, em dois momentos síncrona (whatsapp) foi investigando quais eram as atividades que os alunos do campo desenvolvem em casa? Assíncrona, com registro através de fotos atividades do cotidiano. Neste momento o DEA tem liberdade de escolher quais tarefas a ser relatada para o grupo.

$\mathrm{O}$ momento inicial desenvolvido no projeto do $\mathrm{EH}$ de modo síncrono e assíncrono foi o da Problematização Inicial (PI):

[...] Organiza-se momento de tal modo que os alunos sejam desafiados a expor o que estão pensando sobre as situações. Inicialmente, a descrição feita por eles prevalece, para o professor ir conhecendo o que pensam. [...] é fazer com que o aluno sinta a necessidade da aquisição de outros conhecimentos que ainda detém, ou seja, procura-se configurar a situação em discussão como um problema que precisa ser enfrentado. (DELIZOICOV; ANGOTTI; PERNAMBUCO, 2011, p. 200 e 201).

Organização do Conhecimento (OC): neste momento o professor fez a seleção dos conteúdos e conceitos a serem estudados, aprofundados e discutidos por meio de diferentes atividades, de forma que as problematizações e questões discutidas na Problematização Inicial possam ser respondidas e o aluno possa se apropriar do conhecimento. (DELIZOICOV, 2005). Qual é o tempo?

A OC os alunos estarão de modo síncrono participando da aula através da chamada de vídeo junto com a professora para orientação da tarefa a ser realizada, sendo ela_escrever pequenas frases relatando o que aparece nas fotos. E de forma assíncrona o DEA deve fazer a releitura de uma foto em a folha com lápis de cor; também de forma assíncrona o DEA deve assistir três vídeos no YouTube são eles: zona urbana x zona rural, Chico Bento: a hora da onça beber água e Chico Bento na roça é diferente.

O momento seguinte desenvolvido no projeto foi chamado de Organização do Conhecimento (OC) que exige participação do aluno DEA na reorganização de habilidades e competência.

Os conhecimentos selecionados como necessários para a compreensão dos temas e da problematização inicial são sistematicamente estudados neste momento, sob a orientação do professor. As mais variadas atividades são então empregadas, de modo que o professor possa desenvolver a conceituação identificada como fundamental para uma compreensão científica das situações problematizadas. (DELIZOICOV; ANGOTTI; PERNAMBUCO, 2011, p.201).

Aplicação do Conhecimento (AC): momento destinado a sistematização do conhecimento construído pelo aluno, para analisar e interpretar tanto as situações 
ligadas a temática inicial de estudo, quanto as suas influências externas. (DELIZOICOV, 2005).

A AC produção e apresentação do power point produzido coletivamente entre os três alunos citados anteriormente, onde demonstra-se os resultados do trabalho realizado no período de $20 \mathrm{~h}$ entre os dias 01/09 a 06/10 de 2020.

A aplicação do conhecimento (AC), definido como:

Destina-se, sobretudo, a abordar sistematicamente o conhecimento que vem sendo incorporado pelo aluno, para analisar e interpretar tanto as situações iniciais que determinam o estudo como outras situações, que embora não estejam diretamente ligadas ao motivo inicial, podem ser compreendidas pelo mesmo conhecimento. (DELIZOICOV; ANGOTTI; PERNAMBUCO, 2011, p.202).

Essa combinação foi caracterizada por Christensen, Horn, Staker (2013), como Ensino Híbrido (EH) do inglês Blended Learning (b_Learning), que busca combinar o ensino de forma tradicional de sala de aula com novas abordagens educacionais e tecnológicas.

Por fim, apresenta-se algumas reflexões a respeito das fotos recebidas pelos alunos, onde é visível o contato com o campo, como atividades de pesca, jardim, lavoura, padaria do interior, contato com animais, cuidado com casa entre outras coisas possíveis de conhecer a qualidade de vida e as atividades realizadas pelos alunos do campo.

\section{Resultados da elaboração e desenvolvimento do trabalho utilizando as tecnologias digitais}

Os resultados da elaboração e desenvolvimento do trabalho utilizando as tecnologias digitais, foi apresentado com capricho e dedicação pelos participantes, pois foram vários registros fotográficos e realização de todas as propostas, recebidas pelos alunos da EI, onde percebeu-se a participação e envolvimento de todos.

Abaixo demonstração da primeira tarefa que era registrar com fotos atividades realizadas em casa, onde o DEA era o autor principal no manuseio do celular e a escolha dos locais que ele deveria registar. Seleção de alguns registros recebidos pelos alunos da EI, participantes do AEE. 
Título: fotos a qualidade de vida dos alunos do campo com dificuldades específicas de aprendizagem.

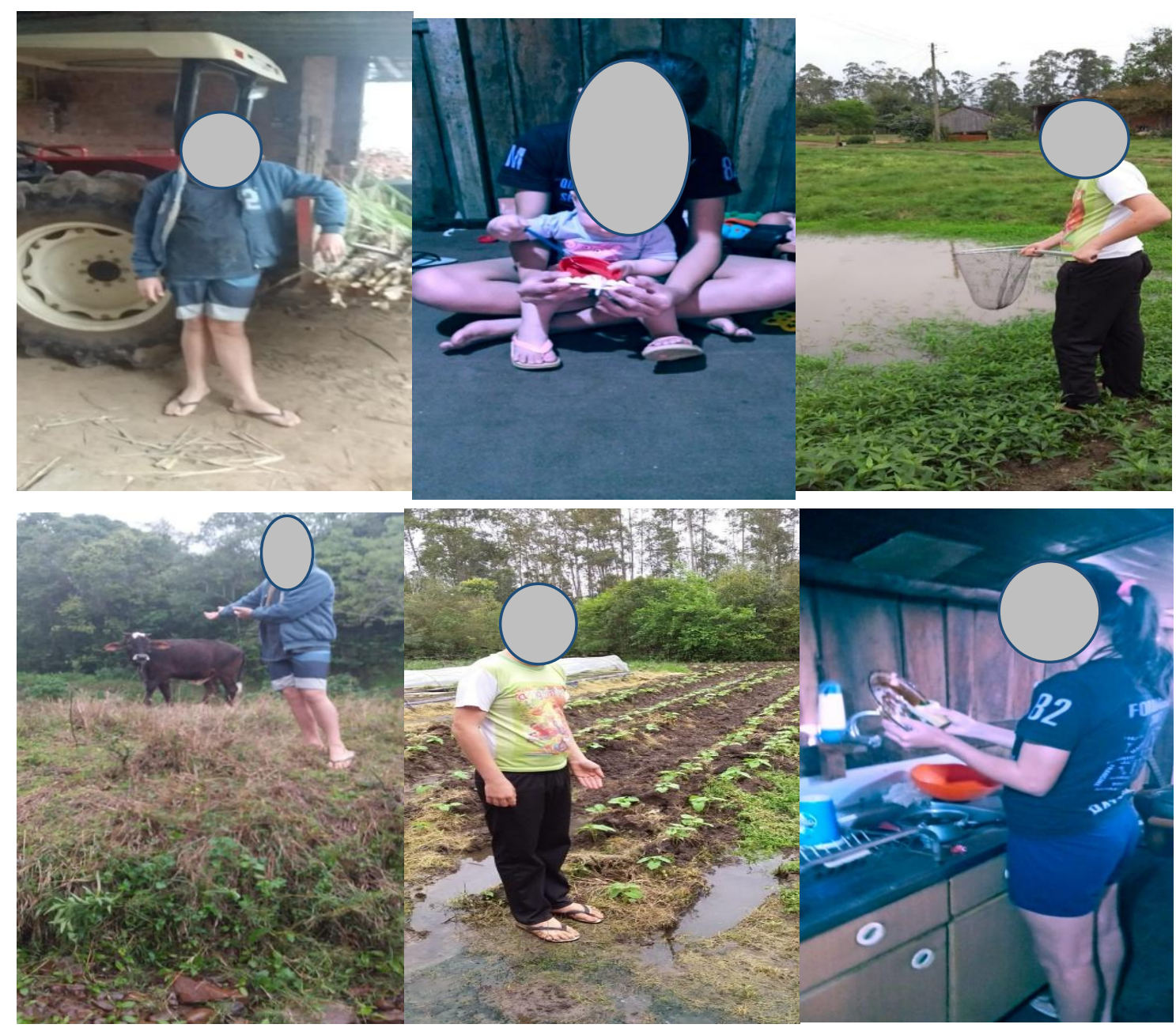

\section{Elaborado pelos autores}

Nestas imagens é possível conhecer a qualidade de vida e as atividades realizadas no campo, os indivíduos exploram a natureza também como meio de sobrevivência, no sentido que muitos deles vivem da produção de alimentos e fumo, o que gera a economia e renda da família.

O relato dos alunos com DEA mencionam a importância desta pesquisa na compreensão da qualidade de vida dos alunos do campo. Eles explicam que os jovens ajudam os pais no dia a dia da propriedade e muitos estão indo embora, pois falta incentivo do governo. E que não se tem internet de boa qualidade e faltam verbas para incentivar eles a ficar no meio rural. Contam, também, que ajudam a mãe plantar feijão, cebola, repolho, alho tomate e moranguinhos para o consumo da família e para vender. Assim como produzem verduras na horta. Tem criação de animais são várias galinhas e peru. E inclusive cuidam de um jardim muito colorido. Para a secagem do fumo e para o fogão eles tiramos lenha de eucalipto. Percebe-se que os alunos gostam muito da vida 
do campo. Outras tarefas realizadas são ajuda a lavar a louça e nas tarefas de casa. Cuida sozinha do seu quarto, também recolhe as roupas e dobra. E adora cuidar e brincar com sua maninha.

Um dos alunos relata que auxilia na produção de pães na padaria da família. E que também cuida da sua avó, ele adora brincar no campo e hoje está construindo um carrinho gigante de madeira e com rodas com auxílio de seu tio.

Acima as imagens demonstram-se os resultados dos participantes envolvidos na atividade, foram muitas fotos recebidas onde fica claro o interesse em mostrar sua qualidade de vida no campo, fazendo uso das tecnologias digitais para expressar o cotidiano do aluno, em meio a horta, aos animais, ao racho e as lenhas que são utilizadas em várias tarefas.

Sendo assim, a abordagem do conhecimento científico da aprendizagem do aluno, considerado o ponto inicial do estudo, pois investigou-se a bagagem de conhecimento por parte dos indivíduos, que utilizou a problematização do conhecimento em primeiro momento o tema desenvolvido foi a qualidade de vida do aluno do campo, a seleção e organização do conhecimento, ocorreu com a expressão visual através de vídeos e releitura das imagens.

Houve uma saída de campo com objetivo de investigação pelos alunos e depois socializaram as experiências com os demais participantes de modo ilustrativo. A atividade oportunizou conhecer alternativas possíveis, e vários aspectos positivos em culturas em meio rural.

A experiência foi de muita relevância para os alunos da EI pois todos entregam a releitura da foto, que estão demonstradas abaixo: 
Título: Releitura das fotos registradas pelos alunos com dificuldades específicas de aprendizagem
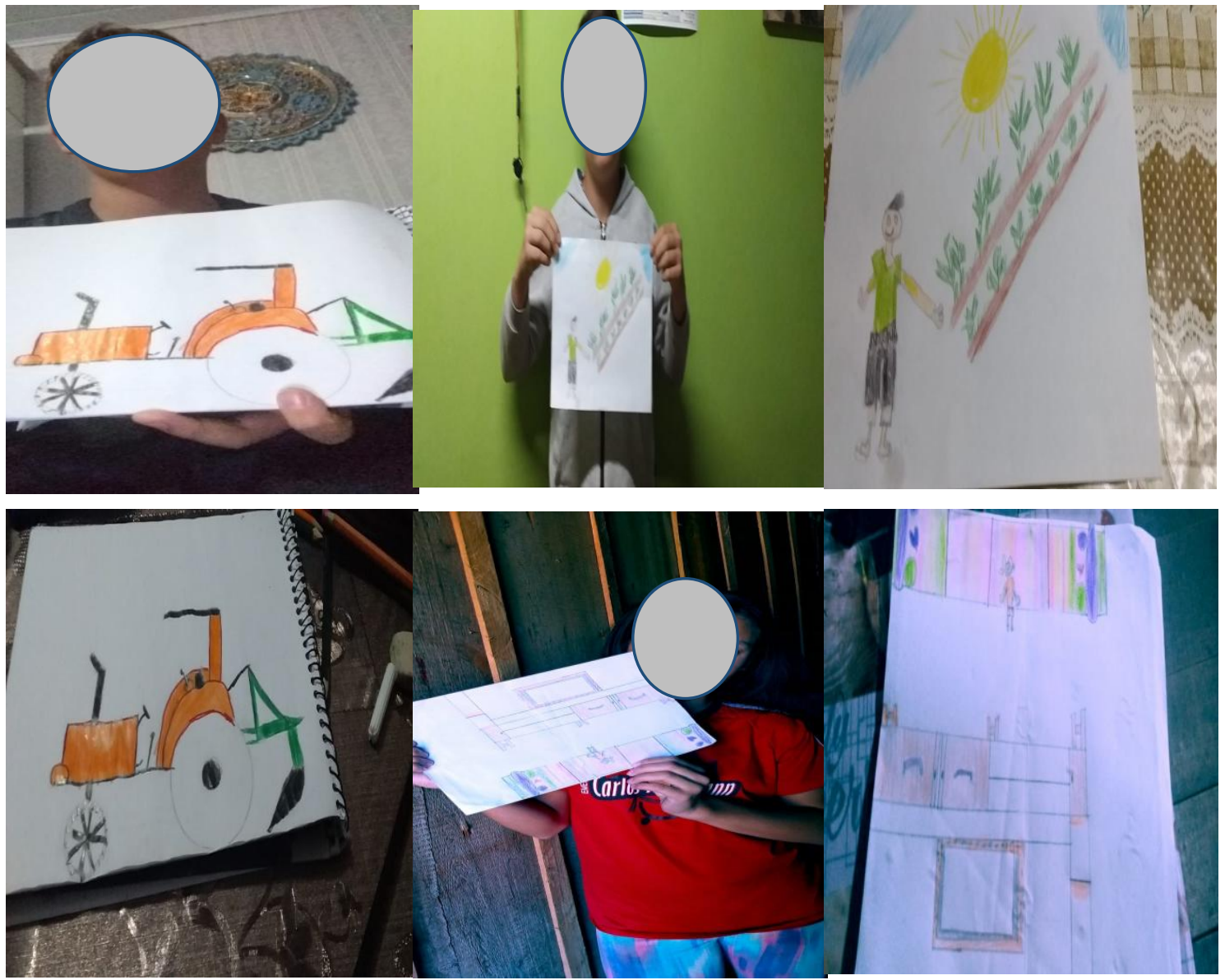

Elaborado pelos autores

Nesta etapa aplicação do conhecimento, responsável em sistematizar o conhecimento trabalhado anteriormente pelo aluno, para analisar e interpretar várias situações abordadas, que foi sendo construída nas etapas de forma síncrona e assíncrona ligadas ao tema inicial, foi compreendida pelos três participantes os conhecimentos.

Por fim, concluiu-se o trabalho com a produção de power point demonstrando toda a sequência didática, e explorado de modo visual pelos alunos com DEA, e todos realizaram a leitura do material.

\section{Considerações finais}

O significativo deste trabalho foi perceber que os três estudantes com DEA conseguiram desenvolver as habilidades necessárias para utilizar as tecnologias digitais, durante o manuseio do celular, e recebendo as orientações básicas para desenvolver as tarefas por meio de vídeo chamadas e leitura de mensagem em grupos, e relevante perceber que todos possuem capacidade de compreensão em modo remoto. 
Durante a experiência vivida neste período de Pandemia e isolamento social, onde houve a necessidade de haver mudança no desenvolvimento do planejamento para manter o vínculo sendo este fundamental no processo de ensino e aprendizagem, ainda mais para este público com DEA.

Só foi possível o contato com o ensino híbrido, e através do grupo do whatsapp foi possível entender que essas famílias não têm computadores e internet de pouca qualidade, muitos utilizam somente dados móveis no celular. Depois da coleta destes dados foi possível realizar o plano de ensino- ensino híbrido utilizando as seguintes ferramentas: facebook, youtube e whatsapp.

Desse modo, EH vem muito a auxiliar este processo de transformação escolar, percebe-se que a tecnologia é uma ferramenta criativa e inovadora no processo de construção das habilidades e competências a serem desenvolvidas no aluno, com a mediação do professor que estará de algum modo orientado no desempenho das atividades de modo síncrono e deixando as tarefas a ser realizadas de modo assíncrono pelo DEA.

\section{Referências bibliográficas}

ALMEIDA, L,B. Os três momentos pedagógicos na Educação Infantil: experiências práticas de Educação Ambiental. RELACult - Revista Latino-Americana de Estudos em Cultura e Sociedade Revista Latinoamericana de Estudios en Cultura y Sociedad | Latin American Journal of Studies in Culture and Society V. 06, edição especial, maio, 2020, artigo no 1689 | claec.org/relacult e-ISSN: 2525-7870.

CECÍLIO, C. Ensino híbrido: quais são os modelos possíveis? Conheça os modelos e as heranças da pandemia para o ensino híbrido no retorno presencial das atividades escolares. 09 de setembro de 2020.

HUDSON, D. Dificuldades específicas de aprendizagem: ideias práticas para trabalhar com: dislexia, discalculia, disgrafia, dispraxia, Tdah, TEA, Síndrome de Asperger, TOC.- Petrópolis, RJ: Vozes, 2019.

SANTOS, M,C. BRITTO, N,S. Os três momentos pedagógicos como possibilidade de aproximação entre a escola e a vida do campo.

SCHIEHL, E, P. GASPARINI, I. Modelos de Ensino Híbrido: Um Mapeamento Sistemático da Literatura. VI Congresso Brasileiro de Informática na Educação (CBIE 2017)- Anais do XXVIII Simpósio Brasileiro de Informática na Educação (SBIE 2017). 1 PPGECMT, 2 PPGCA, Centro de Ciências Tecnológicas Universidade do Estado de Santa Catarina (UDESC) - Joinville - SC - Brasil

TOMAZINHO, P. Ensino remoto emergencial: a oportunidade da escola criar, experimentar, inovar e se reinventar. SINEPE/RS. 17/04/2020 